Bull. Mater. Sci., Vol. 16. No. 3, June 1993. pp. 159-170. (. Printed in India.

\title{
Electron microscopic studies of vacuum-evaporated $\left(\mathrm{Pb}_{1-x} \mathrm{Sn}_{x}\right)_{1-y} \mathrm{Te}_{y}$ thin films
}

\author{
S C DAS ${ }^{\dagger}$, S BHATTACHERJEE ${ }^{\dagger}$ and A K CHAUDHURI* \\ Department of Physics, Indian Institute of Technology, Kharagpur 721 302, India \\ ${ }^{+}$Department of Physics, Midnapore College, Midnapore 721 101, India
}

MS received 14 May 1990; revised 20 August 1991

\begin{abstract}
Thin films of $\left(\mathrm{Pb}_{1-x} \mathrm{Sn}_{x}\right)_{1-y} \mathrm{Te}_{y}$ have been deposited by vacuum evaporation onto glass, mica, $\mathrm{CaF}_{2}$ and $\mathrm{NaCl}$ substrates heated to various temperatures at low deposition rates. Transmission HEED, TEM and SEM studies have been carried out for as-grown films. HEED photographs show that (i) the degree of crystallinity of the films improves at higher substrate temperatures and (ii) the crystallites have smaller dimensions on $\mathrm{CaF}_{2}$ than on $\mathrm{NaCl}$, mica and even glass, under identical conditions of deposition. SEM studies reveal that with increasing $T_{\text {sub }}$, grains tend to form clusters through mobility coalescence. Needleshaped grains are formed when the deposition rate exceeds a certain critical value. Formation of needle-like grains has been attributed to the excess Te atoms possessing trigonal structure so that such grains can be observed only in p-type PbSnTe films.
\end{abstract}

Keywords. Pb-Sn-Te films; vacuum evaporation; electron microscopy.

\section{Introduction}

PbSnTe is a useful IR-sensitive narrow gap semiconductor. The physical properties of thin films depend significantly on their crystallinity and lattice imperfections-both structural and chemical. We had earlier adopted the variance analysis method of $\mathrm{X}$-ray line profiles to determine the crystallinity and certain structural defect parameters of some PbSnTe films deposited by single-boat vacuum evaporation onto heated $(457 \mathrm{~K})$ mica, glass and $\mathrm{NaCl}$ substrates (Das et al 1991). However, such analysis could not be performed on films similarly deposited on polished and (111)-cleaved $\mathrm{CaF}_{2}$, because the prominent peaks of PbSnTe were masked either completely or partially by those from the $\mathrm{CaF}_{2}$ itself. This difficulty is largely obviated in transmission electron micrograph which gives the crystallite size in the plane of the films by direct observations (Wissmann 1975). In contrast, measurements from $X$ line profiles give the average crystallite size perpendicular to the corresponding reflecting planes, the individual microcrystals being capable of diffracting X-rays coherently. On the other hand, TEM photographs show the type of islands, which may or may not be a single crystal.

Since high energy electrons having smaller wavelengths interact with a substance more intensively than X-rays, microcrystalline structure of thin films can be ascertained from transmission high energy electron diffraction (HEED) experiments. Scanning electron micrographs (SEM) permit efficient observation of three-dimensional structures on the surface of thin films. Electron microscopic studies have therefore become imperative not only for microstructural analysis of $\mathrm{PbSnTe}$ layers on $\mathrm{CaF}_{2}$

*For correspondence 
in particular but may supplement the results of X-ray analysis already performed (Das et al 1991) for layers on glass, mica and $\mathrm{NaCl}$ substrates.

\section{Experiments}

Powdered samples of $p$-PbTe (obtained from BARC, Trombay, India) and $p$-SnTe (synthesized in vacuum) were taken in a mass ratio-1.0013:1.7357, the masses being measured in a Mettler balance. The corresponding mole fraction $\left(x^{\prime}\right)$ of SnTe in the mixed compound $(\mathrm{PbTe})_{1-x}\left(\mathrm{SnTe}_{x^{1}}\right.$ was equal to $0 \cdot 702$. The mixture was fused at $\sim 1248 \mathrm{~K}$ in a quartz tube in vacuum $\left(\sim 6.66 \times 10^{-3} \mathrm{~Pa}\right)$ to produce a pseudo-binary $p$-PbSnTe in polycrystalline form. Its composition, as determined by energy-dispersive analysis by $\mathrm{X}$-rays (EDAX-model Camscan, series $2 \mathrm{DV}$ with link analytical systems) is given by $\left(\mathrm{Pb}_{1-x} \mathrm{Sn}_{x}\right)_{1-y} \mathrm{Te}_{y}$, where $x \simeq 0.71$ and $y \simeq 0.51$. Thus the sample was found to be Te-rich (or metal-deficient). This is consistent with its phase diagram (Herman and Melngailis 1974), which shows that the composition of PbTe at the maximum melting point is Te-rich and shifts to become still richer in Te as $\mathrm{Sn}$ replaces $\mathrm{Pb}$ in the lattice.

Thin layers of the above material were deposited on glass, freshly cleaved mica (amber), polished and (111)-cleaved $\mathrm{CaF}_{2}$ and (naturally grown) $\mathrm{NaCl}$ substrates by vacuum evaporation in a Hind Hivac coating unit (base vacua $\sim 4 \times 10^{-3} \mathrm{~Pa}$ ). Substrates were maintained at different temperatures $(\sim 300-457 \mathrm{~K})$ during different depositions. The deposition rate was always kept low $(\sim 2-5 \mathrm{~nm} / \mathrm{min})$ (Das et al 1991). Thicknesses of the films were measured by Fizeau's interference method. Results of EDAX analysis showed that the films possessed higher Te-excesses $(y-0.5)$ and lower Sn-contents $(x)$ than those in the bulk.

Transmission HEED and TEM studies were performed in an electron microscope (AEI-EM6) operated at $100 \mathrm{kV}$ with a maximum resolution of $1.0 \mathrm{~nm}$. Samples were prepared following the carbon replica technique. However, the carbon-coated specimens had to be made thinner by dissolving the film material in dilute $(10-15 \%)$ nitric acid. Photographs were taken on diapositive plates $\left(0.095 \times 0.08 \mathrm{~m}^{2}\right)$, the exposure times being about 10-20 s. SEM photographs were taken for the as-grown films in another electron microscope (Philips, PSEM-500) operated at $50 \mathrm{kV}$. Thin gold layers $(\sim 3-5 \mathrm{~nm})$ were deposited on the samples and photographs taken at suitable tilt angles.

\section{Results and discussion}

\subsection{HEED studies}

These studies were carried out on as-deposited (but thinned) films grown on different substrates at various temperatures. Growth of crystallinity in the films was better revealed by transmission HEED photographs (figures 1a to d). Figure 1a shows that at lower substrate (glass) temperatures $\left(T_{\text {sub }} \sim 373 \mathrm{~K}\right)$, small spots as well as diffuse rings appear. Though the diffuse rings characterize the amorphous nature of the film-material, a degree of short-range order may also be associated with them. When $T_{\text {sub }}$ was increased to $(457 \pm 5 \mathrm{~K})$, the order of vacuum and the deposition rate being nearly similar, the diffuse rings disappear and the spots become larger and brighter 

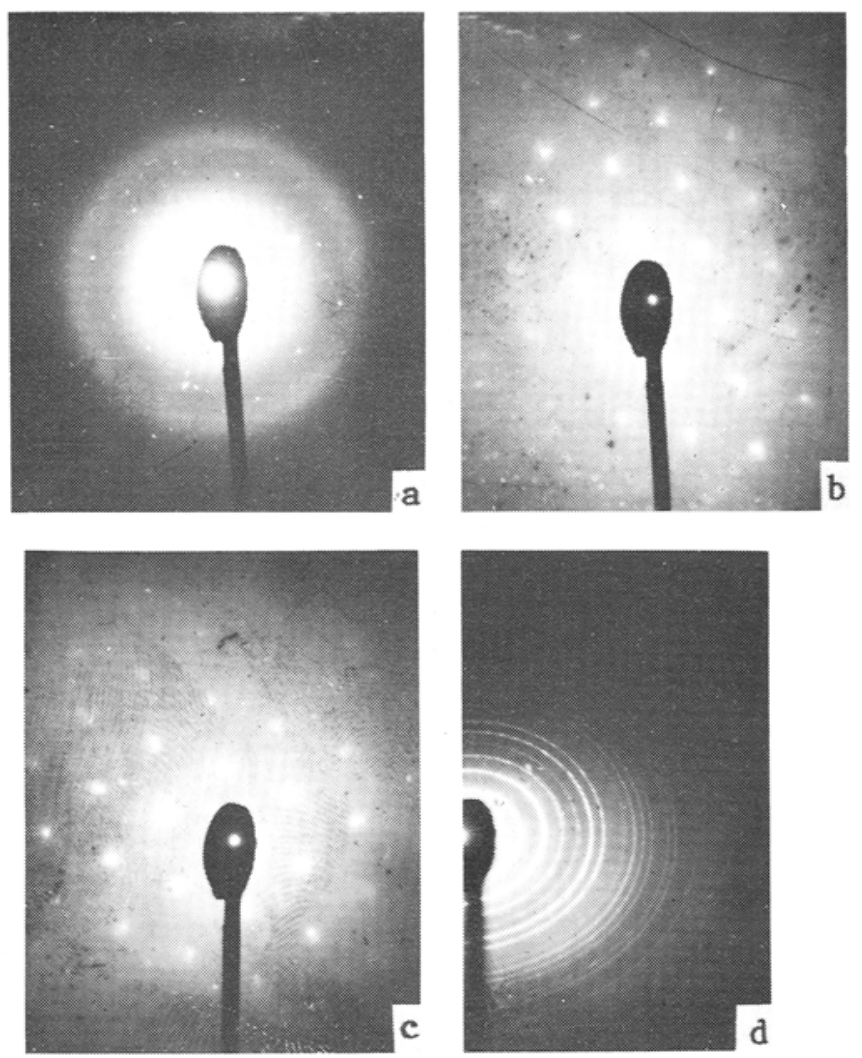

Figure 1. Transmission HEED $(100 \mathrm{kV})$ patterns for $\mathrm{PbSnTe}$ thin films as-deposited on (a) glass $(\sim 373 \mathrm{~K})$, (b) glass $(\sim 457 \mathrm{~K})$, (c) mica $(\sim 457 \mathrm{~K})$ and (d) (111)-cleaved and polished $\mathrm{CaF}_{2}(\sim 457 \mathrm{~K})$.

(figure 1b). This implies that the degree of crystallinity of the films improves at a higher substrate temperature (kept below a certain optimum value that is not determined in this analysis) at the expense of disorder. Similar results have been obtained with mica (figure 1c) and $\mathrm{NaCl}$ substrates.

Though only spots appear in HEED photographs (figure $1 \mathrm{~b}, \mathrm{c}$ ) the films concerned are not truly mono-crystalline; they are actually polycrystalline as revealed by XRD (Das et al 1991). Since the electron beam has a very small sross-section and the sizes of the crystallites parallel to the substrates, surfaces are likely to be fairly large (Das et al 1991), the spots in the said HEED photographs correspond to individual monocrystallites only.

Figure 1d shows halves of the Debye rings obtained with PbSnTe films deposited onto (111)-cleaved and polished $\mathrm{CaF}_{2}$. These films were deposited along with those on glass and mica for which HEED photographs (figure $1 \mathrm{~b}, \mathrm{c}$ ) show only spots. Thus, $T_{\text {sub }}(\sim 457 \mathrm{~K})$ and other deposition parameters were identical for the films corresponding to figures $1 \mathrm{~b}, \mathrm{c}, \mathrm{d}$. Indexing of figure $1 \mathrm{~d}$ reveals that a large number of rings corresponding to reflections having indices (200), (220), (222), (420), (422), (600), (620), (622), (640) and (642) appear with appreciable intensities. Also, some more rings having weaker intensities and corresponding to intermediate or still higher order of reflections 
appear in the negative of the photograph, while with XRD, peaks corresponding to the highest sets of indices (420) only could be noticed with similar films on other substrates (Das et al 1991). This establishes a greater efficacy of the TED technique in micro-diffractions.

An analysis of the said photograph leads to the following conclusions: (i) thin films of $\mathrm{PbSnTe}$, deposited on polished and (111)-cleaved $\mathrm{CaF}_{2}$ are polycrystalline at $T_{\text {sub }}=(457 \pm 5) \mathrm{K}$. Similar results have been obtained with $\mathrm{CaF}_{2}$ by other workers using single-boat evaporation (as in this work) for $T_{\text {sub }}=473-573 \mathrm{~K}$ (Farinre 1970) and even with flash evaporation (Kasai 1970) for $T_{\text {sub }}<488 \mathrm{~K}$, (ii) the sizes of the $\mathrm{PbSnTe}$-crystallites are much smaller on $\mathrm{CaF}_{2}$ than on identically maintained glass, mica or $\mathrm{NaCl}$, because with the same analysing electron beam, the grains formed on glass and mica are monocrystalline (figure $1 \mathrm{~b}, \mathrm{c}$ ) while those on $\mathrm{CaF}_{2}$ are polycrystalline (figure 1d); (iii) PbSnTe-microcrystals show preferences for certain orientations on $\mathrm{CaF}_{2}$, which can be arranged in a descending order as (200), (220), (420), (222) and (422). This is revealed by the stronger intensities of the corresponding rings. The sizes of the grains in the plane of the substrates also vary in the same order from a higher to a lower value.

Thus, in general, the degree of crystallinity of PbSnTe films deposited on heated $(\sim 457 \mathrm{~K})$ mica, glass or $\mathrm{NaCl}$ (natural) substrates is superior to that of the films deposited on (111)-cleaved $\mathrm{CaF}_{2}$ under identical conditions. This may be viewed upon as the combined effect of the following factors: (i) PbSnTe is not isostructural with $\mathrm{CaF}_{2}$, though it ( $\left.\mathrm{PbSnTe}\right)$ is so with $\mathrm{NaCl}$, (ii) while $\mathrm{CaF}_{2}$ cleaves along the (111)-planes, PbSnTe-crystallites prefer (100)-oriented growth even on glass (Das et al 1991) and (iii) the lattice-misfit $\left(\Delta a / a_{\mathrm{PbSnTe}}\right)$ that $\mathrm{PbSnTe}$ (bulk) has with $\mathrm{CaF}_{2}$ is $15.1 \%$ which is greater than the value of the same parameter (viz $11.3 \%$ ) for $\mathrm{NaCl}$ substrates and also the Royer's limit (viz. $15 \%$ ) for the occurrence of epitaxy.

Though the thermal expansion coefficients of $\mathrm{CaF}_{2}\left(=19 \times 10^{-6} \mathrm{~K}^{-1}\right)$ (Kasai 1970) and $\mathrm{PbTe}\left(=16.3 \times 10^{-6} \mathrm{~K}^{-1}\right)-\mathrm{SnTe}\left(=17.6 \times 10^{-6} \mathrm{~K}^{-1}\right)$ solid solutions (Friek et al 1980) are quite closer than to those of glass $\left[=(46-71) \times 10^{-7} \mathrm{~K}^{-1}\right]$, mica $\left(36 \times 10^{-6} \mathrm{~K}^{-1}\right)$ and $\mathrm{NaCl}\left(39 \times 10^{-6} \mathrm{~K}^{-1}\right)$ (Holloway and Walpole 1980$)$ respectively, the effect of thermal expansion matching seems to be outweighed by effects of the above factors.

\section{$3.2 S E M$ and TEM studies}

SEM photographs have been taken for as-grown films only (i.e. without etching, doping or heat treatment). Hence they reveal mainly the morphology of growing film-surfaces under various conditions of deposition. Figures $2 \mathrm{a}-\mathrm{c}$ are the SE micrographs of films deposited onto glass substrates heated to $320 \mathrm{~K},(400 \pm 5) \mathrm{K}$ and $(457 \pm 5) \mathrm{K}$ respectively, the other deposition parameters being nearly identical. It is observed that as $T_{\text {sub. }}$ is raised from $320 \mathrm{~K}$ to $\sim 400 \mathrm{~K}$, the particles grow in size (viz from $\sim 0.1 \mu \mathrm{m}$ to $\sim 0.2 \mu \mathrm{m}$ or more). That this growth in size occurs through coalescence is evident from their tendency to form necks and clusters (figure 2b). At a still higher substrate temperature (viz $\sim 457 \mathrm{~K}$ ), coalescence is enhanced and the grains on the surface fail to exhibit ariy regular shape (figure $2 \mathrm{c}$ ).

Almost similar results were obtained with mica (figures $3 \mathrm{a}, \mathrm{b}$ ) and $\mathrm{NaCl}$ (figure 3c) substrates, except that the particle size and microrelief are relatively small on mica at all substrate temperatures (cf. figures $2 \mathrm{a}$ and $2 \mathrm{c}$ with figures $3 \mathrm{a}$ and $3 \mathrm{~b}$ respectively). 

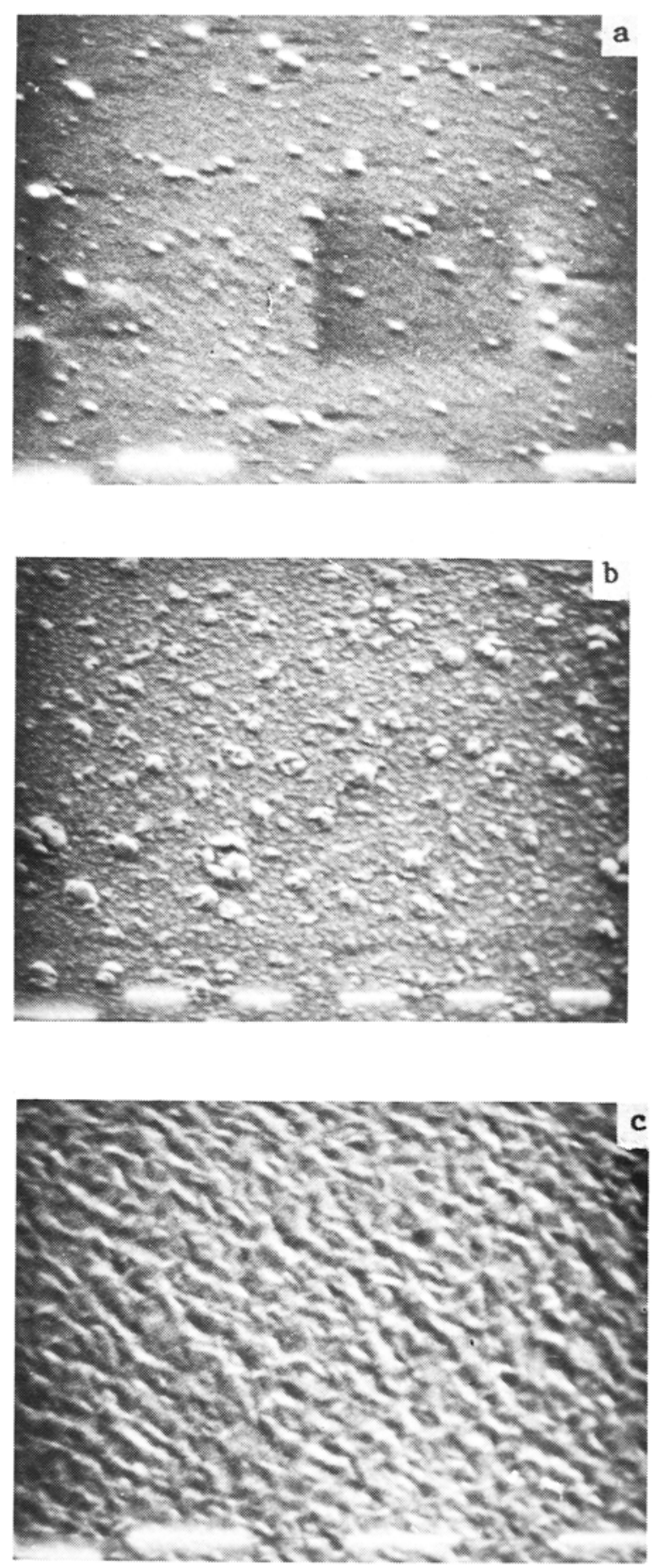

Figure 2. $\mathrm{SEM}$ photographs for $\mathrm{PbSnTe}$ films as-deposited on glass substrates heated to (a) $320 \mathrm{~K}\left(20,000 \times, 30^{\circ}\right.$ tilt), (b) $(400 \pm 5) \mathrm{K}\left(10,000 \times .50^{\circ}\right.$ tilt), and (c) $(457 \pm 5) \mathrm{K}(20,000 \times$, $50^{\circ}$ tilt $)($ scale $=1 \mu \mathrm{m})$. 

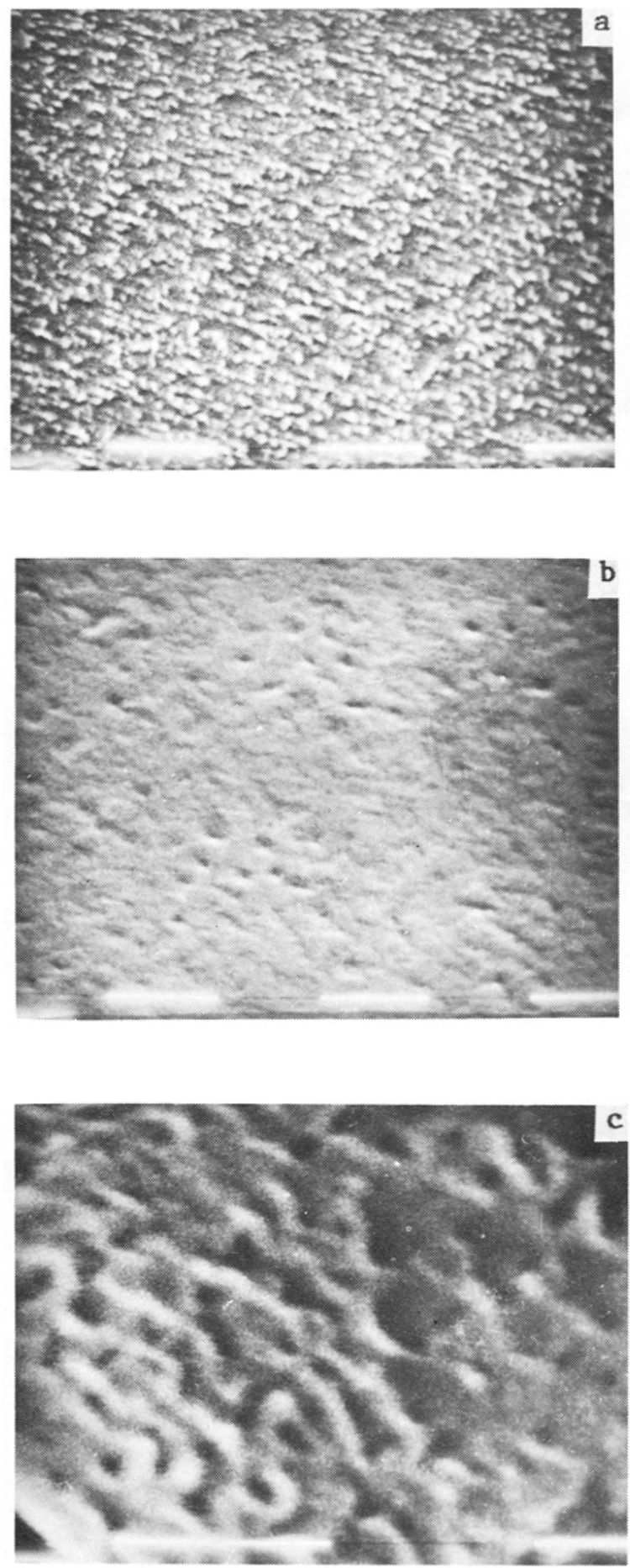

Figure 3. SEM photographs for PbSnTe films as-deposited on (a) mica $\sim 310 \mathrm{~K})(20,000 \times$, $65^{\circ}$ tilt), (b) mica $(\sim 457 \mathrm{~K})\left(20,000 \times, 65^{-}\right.$tilt) and (c) $\mathrm{NaCl}(\sim 457 \mathrm{~K})\left(40,000 \times, 0^{\circ}\right.$ tilt $)$ (scale $=1 \mu \mathrm{m}$ ). 


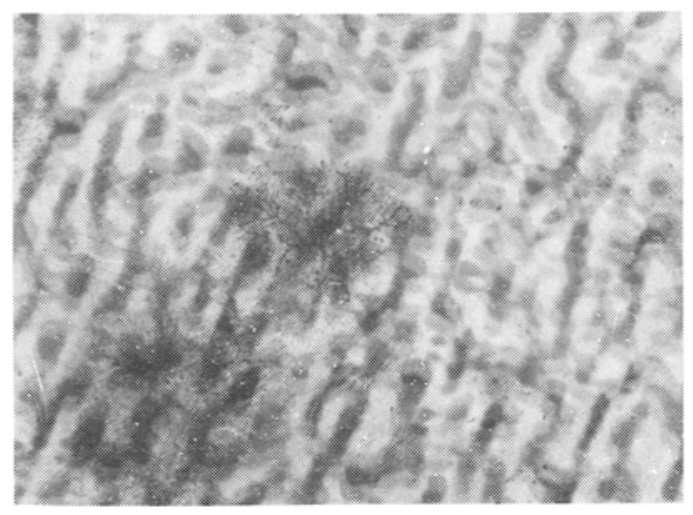

Figure 4. TEM micrograph of a PbSnTe film as-deposited on (111)-cleaved and polished $\mathrm{CaF}_{2}(-457 \mathrm{~K})(50,000 \times$. scale $=0.5 \mu \mathrm{m})$.

Therefore, higher tilt-angles had to be used always for films grown on mica. A comparison of figures $2 \mathrm{c}$ and $3 \mathrm{c}$ shows that the surface pattern of $\mathrm{PbSnTe}$ films deposited under identical conditions (viz. $T_{\text {sub }} \sim 457 \mathrm{~K}$ ) on glass and $\mathrm{NaCl}$ (natural) is almost similar.

TE micrographs were taken for some of the films and they illustrate almost similar results as do the SEM photographs. Figure 4 is a TE micrograph of a $\mathrm{PbSnTe}$ film deposited on $\mathrm{CaF}_{2}$ heated to $(457 \pm 5) \mathrm{K}$. It represents a surface morphology which is very similar to that of a film deposited on glass under identical conditions (cf. figure $2 \mathrm{c}$ ). But the two-dimensional nature of the TEM photographs is their inherent limitation, because of which micro-reliefs on film-surfaces are not clearly revealed.

The results discussed so far may be explained in the following way. The condensing atoms/molecules receive additional thermal energies on a substrate depending on the latter's temperature and nature (viz. thermal conductivity, thickness etc.). Therefore the deposited atoms/molecules have (i) higher mobilities at higher substrate temperatures (for a given substrate) and (ii) different mobilities on different substrates kept at similar temperatures. Improved crystallinity of the films at higher substrate temperatures, as observed in our HEED analysis, is also consistent with the above observations. Because of higher mobilities, the atoms/molecules deposited on substrates kept at higher temperatures move with greater freedom, finally coalescing to form larger coherent domains which can scatter X-rays or electrons coherently. This may be termed as the "mobility coalescence" (Puskeppel and Harsdoff 1976). Moreover, the above observations seem to find justification in the results of our subsequent Hall measurements that majority carriers (i.e. holes in our films) possess (a) higher mobilities in films of similar thicknesses deposited on a given substrate but kept at higher temperatures (investigated up to $\sim 457 \mathrm{~K}$ ) and (b) different mobilities on different substrates kept at similar temperatures during depositions. For example, for films deposited simultaneously onto mica, $\mathrm{NaCl}$ (natural), $\mathrm{CaF}_{2}$ and glass substrates at a given substrate temperature, the hole mobility has been found to have lowest values on mica and gradually higher values on $\mathrm{NaCl}, \mathrm{CaF}_{2}$ and glass respectively.

Figures 5a,b, c represent a set of three SEM photographs for three PbSnTe films deposited under identical conditions on glass (figures 5a,b) and mica (figure 5c) respectively. Here, the substrates were initially kept at the ambient temperature 

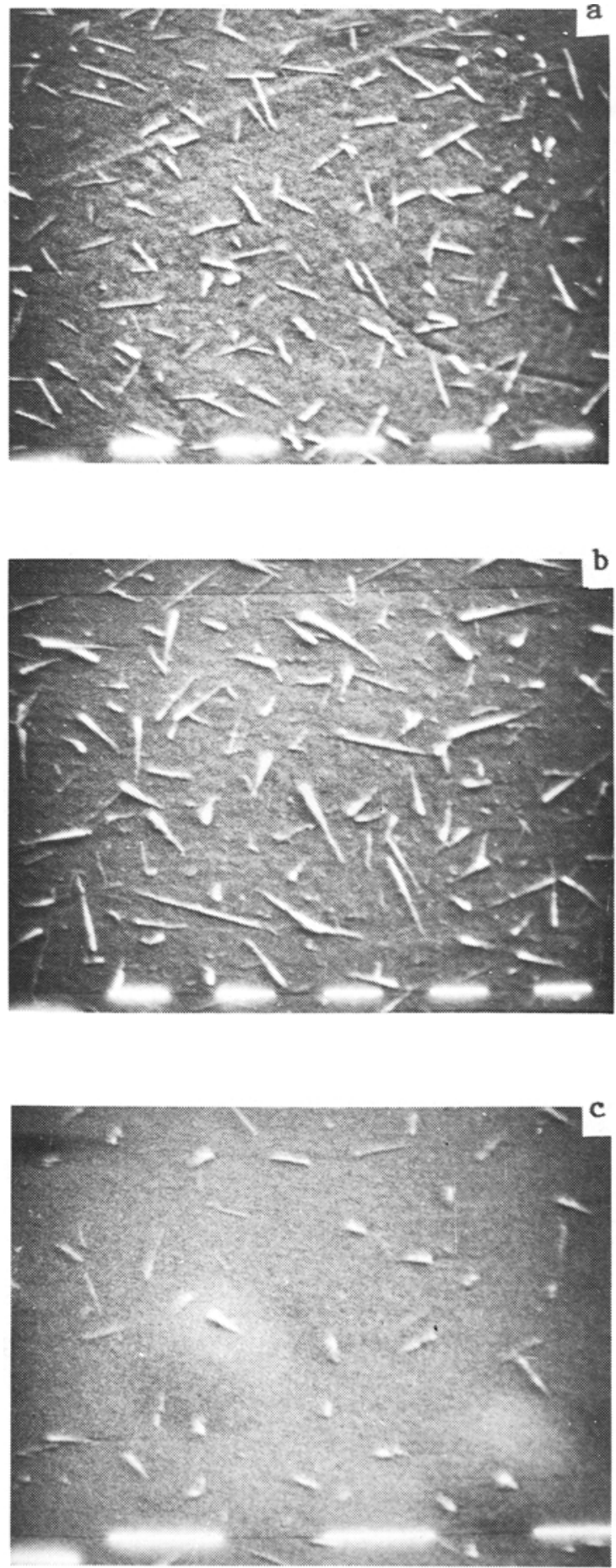

Figure 5. SEM micrographs showing needle-like grains on PbSnTe films as-deposited under identical conditions (Final $T_{\text {sub }} \sim 373 \mathrm{~K}$, rate of deposition $\sim 4.5 \mathrm{~nm} / \mathrm{min}$ ) onto glass (a,b) $\left(10,000 \times, 50^{\circ}\right.$ tilt $)$ and mica (c) $\left(20,000 \times, 50^{\circ}\right.$ tilt), (scale $\left.=1 \mu \mathrm{m}\right)$. 
$(300 \mathrm{~K})$; but when the deposition started, the temperature of the substrates gradually rose to $373 \mathrm{~K}$, the average rate of deposition being $\sim 4.5 \mathrm{~nm} / \mathrm{min}$. The needle-like grains are seen strewn throughout the uppermost surfaces of the films. Figures 5a, $\mathrm{c}$ correspond to glass and mica substrates respectively, which were placed vertically above the source (open $M_{0}$-boat) and figure $5 b$ to that placed horizontally but away from the vertical axis. Two distinct features can be noted from a close examination of the photographs: (i) the needles are much smaller in number as well as in length on surfaces of layers grown on mica than on glass, and (ii) they are more elongated on obliquely placed substrates (both on glass and mica).

Under almost similar conditions of deposition as mentioned above, when $T_{\text {sub }}$ gradually rises from $300 \mathrm{~K}$ to $363 \mathrm{~K}$ in $32 \mathrm{~min}$, the average deposition rate being $\sim 3.0 \mathrm{~nm} / \mathrm{min}$, spherical grains are observed (figure 6) on film-surfaces deposited on glass, which are as noticed earlier for $T_{\text {sub }}=320 \mathrm{~K}$ and at an average deposition $\sim 2.5 \mathrm{~nm} / \mathrm{min}$ (figure 2a). But in this case, the number of grains per unit area is larger. Moreover, from the photograph (figure 6), it is seen that very few needle-shaped grai.is have been formed. Thus, it can be inferred that under nearly similar conditions of deposition, needle-like grains are formed on our $\mathrm{PbSnTe}$ films, when the deposition rate exceeds a certain critical value (viz. $\sim 3.0 \mathrm{~nm} / \mathrm{min}$, as in this case). However, for films deposited on mica under identical conditions as those mentioned above (corresponding to figures $2 \mathrm{a}$ and 6 ), the micro-reliefs on film-surfaces were so small that no SEM photographs could be taken.

Such needle-like topography is also evident from TEM for a thicker PbSnTe film deposited on $\mathrm{CaF}_{2}$ heated to $(457 \pm 5) \mathrm{K}$ (figure 4) and from the SE micrographs for similarly deposited films on glass (figure $2 \mathrm{c}$ ) and on $\mathrm{NaCl}$ (figure $3 \mathrm{c}$ ). However, it appears that the needles have, to some extent, melted away due to the higher temperature $(\sim 457 \mathrm{~K})$ of the substrates. But SEM of an identically deposited film on mica (figure $3 \mathrm{~b}$ ) does not show any needle-like surface morphology.

The formation of needle-like grains at higher deposition rate can be understood as follows: At higher deposition rate, the source temperature and so the final substrate temperature become higher due to radiant heating, particularly when the deposition continues for a sufficient time. At the same time, the surface density of condensed

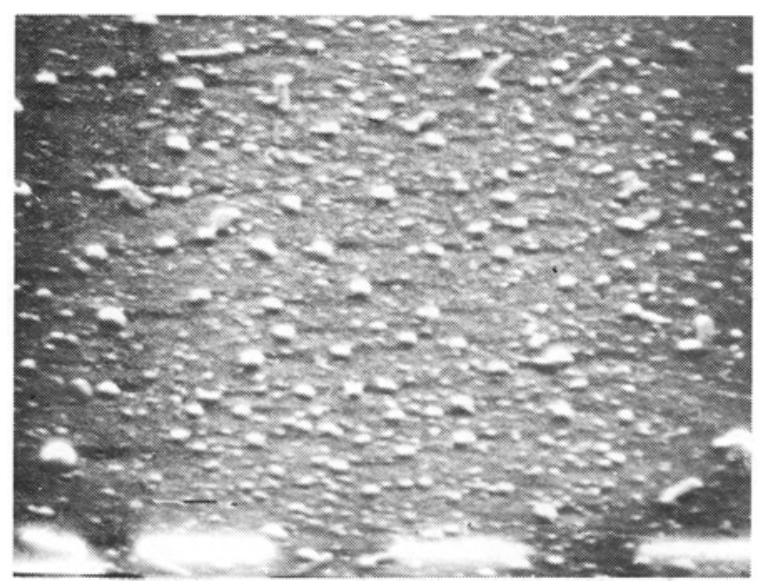

Figure 6. SEM micrograph showing the beginning of needle formation over PbSnTe films as-grown on glass (rate of deposition $-3.0 \mathrm{~nm}$ min) $(20.000 \times$, tilt $=45$, Scale $=1 \mu \mathrm{m}$ ). 
(but unsettled) molecules/atoms increases, all of which have higher mobilities because of increased $T_{\text {sub }}$. The particles therefore touch one another more frequently and form larger grains below a critical deposition rate (viz. $\sim 3 \mathrm{~nm} / \mathrm{min}$ in this case) and needles above it.

However, a question may be raised at this stage as to why the grains develop preferentially into needles. The most probable answer may be found in the following arguments. Since the films have been observed (by EDAX) to have varied Te-excesses and since Te has the trigonal (A 8) structure (Barrett and Massalski) consisting of atoms arranged in hexagonal arrays of helical chains along the $c$-axis with each atom having two neighbours, the needle-like grains may be said to be Te-microcrystals (grown from excess Te), their $c$-axes being parallel to the length of the needles (Shih and Champness 1979). Again, the partial pressures of $\mathrm{Te}_{2}, \mathrm{~Pb}$ and $\mathrm{Sn}$ being in a progressively decreasing order, a certain $(\sim 14 \%)$ fraction (Brebrick and Strauss 1964a, b) of PbTe and SnTe molecules dissociate during evaporations in a scheme:

$$
\mathrm{PbTe} / \mathrm{SnTe} \rightarrow \mathrm{Pb} / \mathrm{Sn}+\frac{1}{2} \mathrm{Te}_{2} .
$$

While the dissociated fraction of PbTe evaporates congruently, that of $\mathrm{SnTe}$ does not because of lower Sn volatility. Moreover, the tendency of dissociation is greater for higher evaporation temperatures. Since our bulk PbSnTe contained a higher mole fraction of SnTe, the films are likely to contain higher Te-excesses at higher evaporation temperatures.

The excess $\mathrm{Te}$ in PbSnTe makes it a p-type semiconductor and both Hall and thermoelectric measurements made subsequently have confirmed that ours is also a $p$-type material. So, it can be said that needle-shaped grains can be observed only in $p$-type films of $\mathrm{PbSnTe}$ and that too under certain conditions of deposition as discussed above. Moreover, the origin of needle-shaped grains observed in the TE micrographs of SnTe films (Santhanam 1982) can be understood in the same way, because undoped $\mathrm{SnTe}$ is always p-type as a result of its $\mathrm{Sn}$-deficiency (i.e. relatively excess $\mathrm{Te}$ ).

The reason for smaller grain sizes/micro reliefs on mica than on glass is not clearly understood. However, two probable explanations based on some assumptions have been attempted here. If the mobility of deposited atoms or molecules on mica is assumed to be less than that on glass (as for the hole mobility), then it may be said that the atoms or molecules incident on mica settle more quickly at numerous preferred sites provided by the crystalline structure of mica; but on glass, the atoms/molecules having greater mobility, move through longer distances to form larger droplets of irregular sizes through 'mobility coalescence', while the grains are almost of equal sizes on mica (cf. figures $2 a$ and 6 with figure $3 a$ ).

An alternative and more probable explanation is based on the modes of growth of the films. From the SEM photographs, it appears that the growth of PbSnTe films on glass follows eicher Volmer-Weber (i.e. particle growth) or Stranski-Krastonov (i.e. initial monolayer growth succeeded by particle growth) modes. But on mica, $\mathrm{PbSnTe}$ films most probably follow the Stranski-Krastonov mode in which the Frank van der Merwe (i.e. monolayer) part plays the dominant role. As a result, the sizes of the particles or needles on upper surfaces of the films deposited on mica are always smaller.

Lastly, figure 7 shows the dislocation network on a PbSnTe film $(300 \mathrm{~nm})$ deposited on mica heated gradually to $368 \mathrm{~K}$ during depositions $(25 \mathrm{~min})$ from an initial 


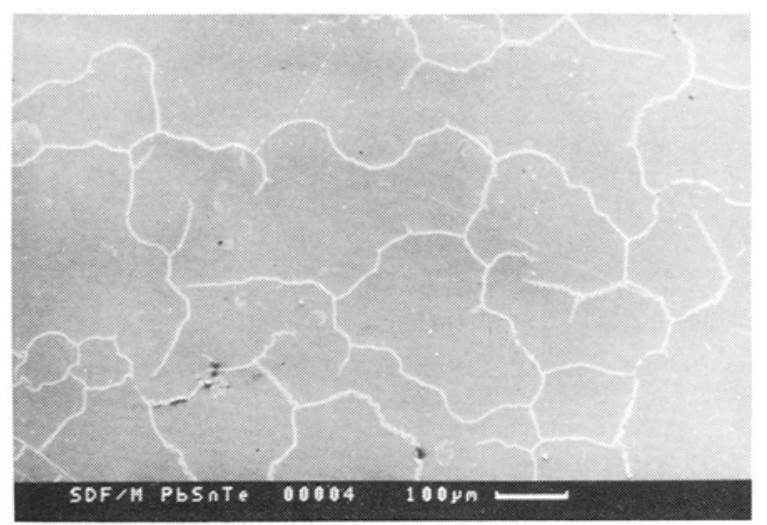

Figure 7. SEM photograph showing the dislocation network on a PbSnTe film as-grown on mica (Final $T_{\text {ub }} \sim 368 \mathrm{~K}$, and rate of deposition $\sim 12 \mathrm{~nm} / \mathrm{min}$ ).

temperature of $323 \mathrm{~K}$. Here, the deposition was performed following Holloway and Walpole (1980) to see if thin film of our pseudo-binary alloy could be deposited without a compositional drift. In addition to using an open $\mathbf{M}_{0}$-boat as in previous depositions, the powdered and homogenized source material was compressed to form a tablet. The rate of deposition was much higher viz. about $12 \mathrm{~nm} / \mathrm{min}$, the order of vacuum being $\sim 5 \times 10^{-3} \mathrm{~Pa}$. However, subsequent compositional analyses of the films by EDAX revealed that they did suffer stoichiometric shifts. But thin films thus deposited on glass showed no dislocation network or microrelief up to highest available magnifications (viz $80,000 \times$ ) in SEM (camscan-series $2 \mathrm{DV}$ with Link analytical system). Films on mica also showed no microrelief between/within dislocation lines/loops.

\section{Conclusions}

The results discussed can be summarized as follows:

(i) The crystallinity of the films is strongly affected by the substrate temperature. As the latter is increased, the former improves at the expense of disorder and the deposited atoms show gradually increasing tendency of cluster-formation and coalescence to produce larger grains, which can be explained on the basis of higher mobilities of deposited aioms/molecules at higher substrate temperatures.

(ii) $\mathrm{PbSnTe}$ crystallites have smaller dimensions on $\mathrm{CaF}_{2}$ than on $\mathrm{NaCl}$, mica or even ordinary glass substrates-all kept under identical conditions.

(iii) Needle-like grains are formed for rates of deposition exceeding a certain critical value viz. $\sim 3 \mathrm{~nm} / \mathrm{min}$ in this case, below which the grains are spherical. Moreover, the needles can be observed only in p-type PbSnTe films which have excess $\mathrm{Te}$ possessing trigonal (A8) structure.

(iv) Sizes of the grains (both spherical and needle-like) and their microreliefs are much smaller on films grown from powdered materials on mica at all substrate temperatures compared to those on the other three substrates used in this investigation. 


\section{References}

Barrett C S and Massalski T B Structure of metals, crystallographic methods, principles and data, (New York: McGraw Hill) Indian reprint (New Delhi: Eurasia Pub. House) 3rd edn. 229

Brebrick R F and Strauss A J 1964a J. Chem. Phys. 403230

Brebrick R F and Strauss A J 1964b J. Chem. Phy's. 41197

Das S C. Samantaray B K. Bhattacherjee S and Chaudhuri A K 1991 J. Mater. Sci. 262595

Farinre T O $1970 \mathrm{Ph}$ D Thesis, Pennsylvania University, USA

Friek D M, Rarenko I M, Solonichnyi Ya V and Shperun V M 1980 Inorg. Mater. 16278

Harman T C and Melngailis I 1974 Narrow gap semiconductor in applied solid state science, (ed.) R Wolfe 41

Holloway H and Walpole J N 1980 in Molecular beam epitaxy (ed) B R Pamplin (Pergamon) pp. 49-94

Kasai I $1970 \mathrm{Ph}$ D Thesis, California University. Los Angeles

Puskeppel A and Harsdorf M 1976 Thin Solid Films 3599

Santhanam S 1982 Ph D Thesis, Dept. of Phys,, IIT, Kharagpur, India

Shih I and Champness C H 1979 in The physic's of tellurium and selenium, Springer Series in Solid St. Sci., (eds) E Gerlach and P Grosse 13267

Wissmann P 1975 Surface physics, springer tracts in modern physics, (ed) G Hohler (Springer-Verlag) 771 